\title{
Flicker Noise Spectroscopy in the Analysis of Electrochemical Noise of Hydrogen-air PEM Fuel Cell During its Degradation
}

\author{
E.A. Astafev ${ }^{1}$, A.E. Ukshe ${ }^{1, *}$, R.A. Manzhos ${ }^{1}$, Yu.A. Dobrovolsky ${ }^{1}$, S.G. Lakeev ${ }^{2}$, S.F. Timashev ${ }^{2}$ \\ ${ }^{1}$ Institute of Problems of Chemical Physics RAS, Acad. Semenov av., 1, 142432, Chernogolovka, \\ Moscow region, Russia \\ ${ }^{2}$ L.Ya. Karpov Institute of Physical Chemistry, Obukha backstr., 3-1/12, bld. 6, 105064, Moscow \\ *E-mail: ukshe@mail.ru
}

doi: $10.20964 / 2017.03 .56$

Received: 6 December 2016 / Accepted: 19 January 2017 / Published: 12 February 2017

\begin{abstract}
A variation in fluctuation dynamics of the noise component of the electric potential of a fuel cell was studied. A fuel cell with polymer membrane and gas diffusion layer was tested and treated with a fast degradation procedure. The characteristics of electrochemical noise were obtained using a flicker noise spectroscopy that provides an analysis of a cosine-spectrum of autocorrelation function and second order difference moment of voltage noise. A sequence of fast degradation steps results in a change of maximum load current of a polymer electrolyte membrane fuel cell. The main effect of fast degradation on the noise parameters is the change in the ratio of areas (i.e. power) of the lowfrequency peak (a range of $\Delta f_{L F}=0.001-0.003 \mathrm{~Hz}$ ) to the high-frequency peak (a range of $\Delta f_{H F}=$ $0.258-0.262 \mathrm{~Hz})$ in cosine-spectrum of the autocorrelation function.
\end{abstract}

Keywords: Fuel cell, degradation, electrochemical noise, flicker noise spectroscopy.

\section{$\underline{\text { FULL TEXT }}$}

(C) 2017 The Authors. Published by ESG (www.electrochemsci.org). This article is an open access article distributed under the terms and conditions of the Creative Commons Attribution license (http://creativecommons.org/licenses/by/4.0/). 